\title{
Using a virtual game system to innovate pulmonary rehabilitation: Safety, adherence and enjoyment in severe chronic obstructive pulmonary disease
}

\author{
Rima Wardini MSc${ }^{1}$, Esther Dajczman MScA ${ }^{1,2}$, Nathan Yang ${ }^{2}$, Marcel Baltzan $\mathrm{MD}^{1,2}$, David Préfontaine PhD ${ }^{1}$, \\ Maria Stathatos BSCPT ${ }^{1}$, Haguit Marciano BScOT ${ }^{1}$, Shawn Watson BScPT ${ }^{1}$, Norman Wolkove MD ${ }^{1,2}$
}

\begin{abstract}
R Wardini, E Dajczman, N Yang, et al. Using a virtual game system to innovate pulmonary rehabilitation: Safety, adherence and enjoyment in severe chronic obstructive pulmonary disease. Can Respir J 2013;20(5):357-361.

OBJECTIVE: The present pilot study tested the use of a virtual game system (VGS) for exercise training in patients with moderate to very severe chronic obstructive pulmonary disease undergoing pulmonary rehabilitation (PR). Safety, feasibility, enjoyment and adherence were assessed.

METHODS: VGS (Wii [2006], Nintendo, USA) games were prescreened and categorized into lower- and upper-body workouts. Patients admitted for a three- to four-week inpatient PR program exercised daily. They were provided an opportunity to individually engage in VGS sessions three times weekly, varying with length of stay. Dyspnea, oxygen saturation and heart rate were measured before, during and after game sessions. Patients were considered to be adherent if they attended at least $50 \%$ of VGS sessions. Adverse events and enjoyment were evaluated.

RESULTS: Thirty-two patients with a mean $( \pm$ SD) age of $66 \pm 9$ years and a mean forced expiratory volume in $1 \mathrm{~s}$ of $0.72 \pm 0.40 \mathrm{~L}$ participated. Among the 25 patients completing the program, adherence was $76 \%$, with a mean attendance rate of $64 \pm 35 \%$. Mean dyspnea score was $1.5 \pm 1.1$ before and $3.2 \pm 1.2$ after exercise. Mean oxygen saturation changed from $94 \pm 3 \%$ to $91 \pm 5 \%(\mathrm{P}<0.001)$, while heart rate increased from $88 \pm 15$ beats $/ \mathrm{min}$ to $102 \pm 18$ beats/min $(P<0.001)$. One patient reported chest pain requiring nitroglycerin spray and five experienced transient desaturation below $85 \%$ with play. Patients enjoyed the program (visual analogue score $8 \pm 2.6 / 10$ ) and most would highly recommend it to others.

CONCLUSIONS: Moderate exercise using a VGS was safe, feasible and enjoyed as an adjunct to inpatient PR. This modality may encourage patients to maintain physical activity after PR.
\end{abstract}

Key Words: Chronic obstructive pulmonary disease; Pulmonary rehabilitation; Virtual game system

Chronic obstructive pulmonary disease (COPD) is the fourth leading cause of mortality in Canada and is associated with significantly decreased quality of life (1-4). Pulmonary rehabilitation (PR) has been shown to be an important component of patient management, with exercise training an essential part of most PR programs. However, having patients maintain higher levels of physical activity after PR remains a significant challenge.

Virtual game systems (VGS) are an innovative way to facilitate physical activity, and have been introduced as a therapeutic modality in the rehabilitation environment (5). The Wii (Nintendo, USA) has now been used clinically in a variety of health care and rehabilitation settings for chronic conditions such as stroke, Parkinson's disease, multiple sclerosis and cognitive impairment $(5,6)$. VGS may help to foster exercise, encourage socialization and improve mastery of activities of daily living. For patients with COPD, however, incorporating VGS in a rehabilitation program has not been extensively studied.

A recent study by Albores et al (7) tested the efficacy of a virtual game technology (Wii) in 20 patients with COPD undergoing a home exercise program. Stable, moderate to severe COPD patients trained for three months, at least five days per week using the Wii Fit system.
L'utilisation d'un système de jeux virtuels pour innover en matière de réadaptation pulmonaire : la sécurité, l'adhésion et le plaisir en cas de maladie pulmonaire obstructive chronique

OBJECTIF : Le présent essai pilote visait à évaluer l'utilisation d'un système de jeux virtuels (SJV) pour l'entrainement à l'exercice chez les patients ayant une maladie pulmonaire obstructive chronique modérée à très grave en cours de réadaptation pulmonaire (RP). Les chercheurs ont évalué la sécurité, la faisabilité, le plaisir et l'adhésion.

MÉTHODOLOGIE : Les chercheurs ont prévisualisé les jeux du SJV (Wii [2006], Nintendo, États-Unis) et les ont classés en entraînement du bas et du haut du corps. Les patients hospitalisés en vue d'un programme de RP de trois à quatre semaines faisaientde l'exercice tous les jours. Ils avaient la possibilité de participer individuellement à des séances du SJV trois fois par semaine, ce qui variait selon la durée d'hospitalisation. On mesurait leur dyspnée, leur saturation en oxygène et leur rythme cardiaque avant, pendant et après les séances de jeu. On considérait que les patients adhéraient au programme s'ils assistaient à au moins 50 \% des séances de SJV. Les chercheurs ont évalué les effets négatifs subis et le plaisir ressenti.

RÉSULTATS : Trente-deux patients d'un âge moyen ( \pm ÉT) de $66 \pm 9$ ans et dont le volume expiratoire maximal par seconde était de 0,72 $\pm 0,40 \mathrm{~L}$ ont participé à l'étude. Chez les 25 patients qui ont terminé le programme, l'adhésion était de $76 \%$, le taux moyen de présence s'établissant à $64 \pm 35 \%$. L'indice moyen de dyspnée s'élevait à $1,5 \pm 1,1$ avant l'exercice et à $3,2 \pm 1,2$ après l'exercice. La saturation en oxygène moyenne a fléchi de $94 \pm 3 \%$ à $91 \pm 5 \%$ $(\mathrm{P}<0,001)$, tandis que le rythme cardiaque est passé de $88 \pm 15$ battements/min à $102 \pm 18$ battements/min $(P<0,001)$. Pendant le jeu, un patient a fait état de douleurs thoraciques qui ont exigé le recours à un atomiseur de nitroglycérine, et cinq ont subi une désaturation transitoire sous les $85 \%$. Les patients ont pris plaisir à participer au programme (indice visuel analogique de $8 \pm 2,6 / 10$ ), et la plupart le recommanderaient chaudement.

CONCLUSIONS : L'exercice modéré au moyen d'un SJV était sécuritaire, faisable et agréable comme ajout à la RP des patients hospitalisés. Cette modalité pourrait encourager le maintien de l'activité physique après la RP.

They found a significant increase in exercise capacity and quality of life, and that this led to exercise maintenance and increased endurance on a shuttle walk test in the short term (7). The authors concluded that although a VGS can offer similar exercise to that available in traditional rehabilitation settings, more research is needed to determine whether it increases adherence to regular workouts at home (8). Limitations of that study included a lack of randomization to a control group. Furthermore, there was no direct supervision during the homebased program, which limited the ability to record adverse events such as significant desaturation.

To better understand the potential use of VGS in patients with COPD, we tested the 2006 Wii VGS as an adjunct to inpatient PR. Our goal was to assess the safety, feasibility, enjoyment and adherence with this therapeutic modality in a supervised setting.

\section{Participants}

\section{METHODS}

Patients admitted to a three- to four-week PR program at Mount Sinai Hospital Centre (MSH, Montreal, Quebec), had been either referred by a physician, community home care service, or transferred from an

${ }^{1}$ Mount Sinai Hospital Centre; ${ }^{2}$ McGill University, Montreal, Quebec

Correspondence and reprints: Mrs Esther Dajczman, Mount Sinai Hospital, 5690 Cavendish Boulevard, Montreal, Quebec H4W $1 S 7$.

Telephone 514-369-2222 ext 2170, fax 514-369-6187, e-mail esther.dajczman.sinai@ssss.gouv.qc.ca 


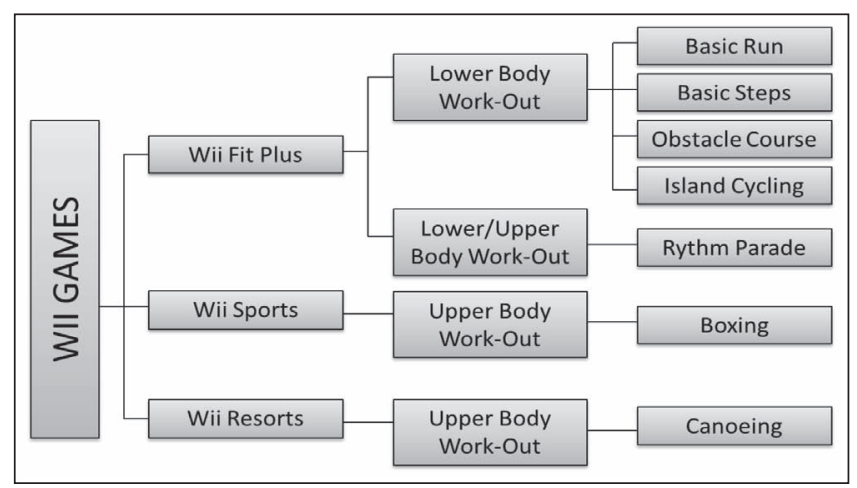

Figure 1) Virtual game system games available for upper and lower body workouts. Patients were asked to exercise the upper and lower body during each virtual game exercise session. Wii Nintendo, USA

acute care hospital. Patients with moderate to severe COPD were screened to participate in the study. Patients were assessed by the health care team to determine whether there were any contraindications to exercise. Individuals with severe cardiovascular disease (ie, unstable angina, acute myocardial infarction, cerebral vascular accident), or physical or psychological impairment potentially impeding exercise were excluded. Individuals with limited life expectancy, unable to answer questionnaires in English or French, or unwilling to provide written informed consent were also excluded.

In addition to daily exercise training within the PR program, patients were provided an opportunity to engage in VGS sessions three times weekly. The number of sessions offered varied with length of stay. Training occurred on an individual basis and was conducted in a dedicated room on the respiratory ward at $\mathrm{MSH}$.

\section{Study procedures}

The protocol was approved by the MSH Research Ethics Committee. Following informed consent, patient medical charts were reviewed. Demographic information, lung function, level of breathlessness using the Modified Medical Research Council Dyspnea Scale (MMRC) (9) as well as pre-existing conditions were recorded. The Mini-Mental State Examination (MMSE) test was administered to screen for cognitive impairment at baseline (10). Functional status was evaluated by the physiotherapist using 6 min walk distance coupled with the Borg Dyspnea Index. Fall risk was assessed using the Berg Balance Scale. Those with a Berg score $<45$ of 56 were determined to have increased risk of fall and were asked to play in a seated position $(11,12)$. Patients with severe dyspnea or those uncomfortable with the standing position were permitted to play seated and, therefore, could be sitting or standing at any time during their session. To allow patients to play seated, the system was adapted by placing weights on the Wii Balance Board platform where the patient would normally stand. This was needed for the system to recognize lower limb weight as if the patient were in the standing position, and to create the patient profile within the computer system.

PR exercise session: The PR program at MSH includes exercise sessions conducted five times weekly. These sessions include resistance and endurance training that is guided by physiotherapy professionals. Resistance training includes movements that target upper and lower body muscle groups to increase strength. The duration of the endurance training, which can be completed on a treadmill or cycle ergometer, is determined based on the patient's actual functional status. However, the aim is for patients to progress throughout their PR program.

Game description: Training occurred on an individual basis and in a dedicated room on the respiratory ward at MSH. Games (Fitness Plus Fun 2009, Wii Sports Resort 2009, Wii Sports 2007) were prescreened by the occupational therapist, the physiotherapist and research personnel to determine suitability for the COPD population. A pool of possible games was assembled for patients to choose from, and divided into lower and upper body workouts (Figure 1). Each individual gaming session respected a specific pattern (Figure 2). Participants played at least

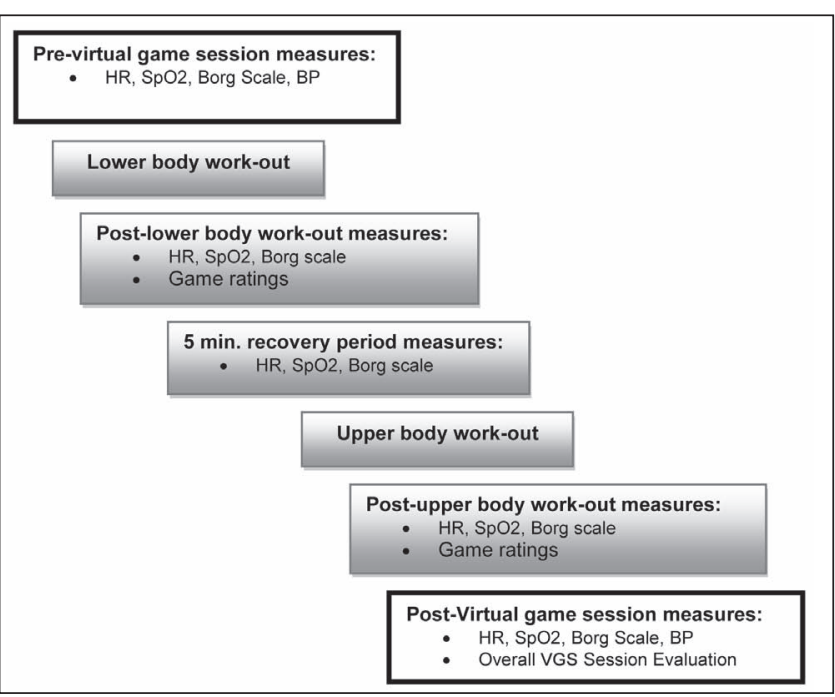

Figure 2) Schematic of a virtual game exercise session and physiological values measured during play. BP Blood pressure; $\mathrm{HR}$ Heart rate; $\mathrm{SpO}_{2}$ Oxygen saturation; VGS Virtual game system (Wii, Nintendo, USA)

two different types of games per session. The first type consisted of an aerobic/lower body workout, and the second involved the upper body. 'Basic Run', 'Basic Step', 'Obstacle Course' and 'Island Cycling' were all games targeting lower body workouts, in which patients were either walking or stepping on the Wii Balance Board. Boxing, which consisted of throwing punches toward a virtual punching bag, and canoeing, which involved paddling motions, were chosen for upper body training. Finally, 'Rhythm Parade', which consisted of stepping on the Wii Balance Board platform and waving the arms to drum, was chosen to target both lower and upper body muscle groups.

Each type of exercise had different game options and levels. Initially, patients received one-on-one instruction on how to play each game and were then able to select from the list of what was made available at each session. No direction was given as to requirements for duration, level or progression of play and choice of game. Patients ended their game and/or session at their discretion and information as to their reason for stopping was noted. Duration of play, level of difficulty and the score attained were recorded. Those playing seated were able to adapt their lower body workout by moving their legs up and down on the platform. It was possible for patients to alternate between standing and sitting position if needed. All of the games mentioned previously involved movements that were similar to those performed in regular PR sessions, such as upper and lower body flexion/extension or walking in place.

Physiological parameters, including oxygen saturation $\left(\mathrm{SpO}_{2}\right)$, heart rate (HR) and dyspnea, were measured using a 10-point Borg scale before and after each session, as well as in between each type of workout for safety purposes. All adverse events were documented.

Patients were offered the opportunity to play three times weekly during the course of their rehabilitation stay and were able to engage in extra gaming sessions at their request. Attendance (sessions attended/sessions offered) and adherence were recorded. Patients were deemed to be adherent with the program if they completed $>50 \%$ of sessions offered. This threshold was chosen because it has been suggested that individuals who attend $<50 \%$ of sessions do not derive noticeable benefit from a PR program (13).

A $10 \mathrm{~cm}$ visual analogue scale (VAS) was used to measure the level of overall enjoyment at the end of the program (14). Patients rated their game preferences in order and a summary of all patient responses was assembled to determine an overall ranking. Patients were also asked if they would recommend this program to others and if they would consider buying the console for home use. Patients were asked to complete a familiarity-with-technology questionnaire adapted from the Canadian Internet Use Survey (15). 
TABLE 1

Patient characteristics ( $n=32$ [11 men, 21 women])

\begin{tabular}{|c|c|c|}
\hline & Mean \pm SD & Min - Max \\
\hline Age, years & $66 \pm 9$ & $52-85$ \\
\hline Body mass index, $\mathrm{kg} / \mathrm{m}^{2}$ & $26.6 \pm 6.1$ & $19.5-40.4$ \\
\hline Pack years & $80 \pm 62.7$ & $7-250$ \\
\hline $\mathrm{FEV}_{1}, \mathrm{~L}$ & $0.72 \pm 0.44$ & $0.29-0.96$ \\
\hline $\mathrm{FEV}_{1}, \%$ predicted & $28.8 \pm 14$ & $16.1-87$ \\
\hline 6MWD on admission, $\mathrm{m}$ & $196.0 \pm 95.8$ & $80.0-280.0$ \\
\hline MMRC & $3.21 \pm 0.96$ & $1-4$ \\
\hline Berg score* & $50.6 \pm 5.5$ & $29-56$ \\
\hline $\mathrm{MMSE}^{\dagger}$ & $27.3 \pm 2.5$ & $23-30$ \\
\hline
\end{tabular}

${ }^{*}$ Berg score $<45$ of 56 increased risk of fall; ${ }^{\dagger}$ Mini-Mental State Examination (MMSE) <25/30 cognitive impairment. 6MWD 6 min walk distance; FEV 1 Forced expiratory volume in $1 \mathrm{~s}$; Max Maximum; Min Minimum; MMRC Modified Medical Research Council Dyspnea Scale

\section{Statistical analysis}

Demographic and physiological parameters, as well as level of enjoyment were compiled. Physiological values (dyspnea, $\mathrm{SPO}_{2}$ and $\mathrm{HR}$ ) were measured before and after each exercise session to assess level of workout. Means and SD were calculated and paired $t$ tests were performed to determine differences. A two-tailed $\mathrm{P}<0.05$ was considered to be statistically significant. Attendance and adherence rates to the adjunct program were recorded and compared with that of the standard PR program.

\section{RESULTS}

A total of 32 patients ( 11 men, 21 women) between 52 and 85 years of age (mean $[ \pm \mathrm{SD}]$ age $66 \pm 9$ years) were recruited into the program (Table 1). Seven patients withdrew from the study. Two patients were not interested in continuing after initially consenting to participate because they believed the games were too simplistic. Three had intercurrent acute illness and two other patients believed the games were too difficult in addition to their regular PR sessions. Baseline pulmonary function values indicated that the majority had severe to very severe disease. The distribution of patients according to GOLD stages II to IV were $13 \%, 10 \%$ and $77 \%$, respectively. Patients had a mean baseline walk distance of $196 \pm 96 \mathrm{~m}$. Only two participants had a Berg balance score $<45$ of 56 , indicative of increased fall risk. A mean MMSE score of $27 \pm 2$ was found, indicating normal cognitive function in this patient sample.

Patients rated their four favourite games. These scores were then summed to determine an overall preferential order for the group, and was as follows: Rhythm Parade, Obstacle Course, Canoeing, Basic Run, Island Cycling, Basic Step and Boxing. The majority (84\%) played at the beginner's level. The average length of time played by patients during each session was 14:22 $\pm 6: 17 \mathrm{~min}$ (range 2:40 min to 39:48 $\mathrm{min}$ ). The most common reasons for ending play were shortness of breath (60\%), fatigue (20\%) and dizziness/headache (12\%).

Mean HR and dyspnea increased significantly and mean $\mathrm{SpO}_{2}$ decreased significantly with game exercise sessions, regardless of whether the patient was in the standing or seated position, suggesting at least moderately challenging physical activity (Table 2).

Six patients experienced adverse events. One patient with moderate COPD and pre-existing coronary artery disease required the use of nitroglycerin spray. Five patients with very severe COPD (GOLD stage IV) experienced a transient $(<30 \mathrm{~s})$ decrease in $\mathrm{SpO}_{2}$ below $85 \%$, but were asymptomatic.

Among the 25 patients who completed the program, the adherence rate was $76 \%$, with a mean attendance rate of $64 \pm 35 \%$. This compared with an adherence rate of $100 \%$, with a mean attendance rate of $88 \pm 13 \%$ for the regular PR program. Eight patients (32\%) requested extra sessions in addition to those already offered.

When asked to rate overall enjoyment, patients reported a mean score of $8.0 \pm 2.6 / 10$ with the adjunct program using a $10 \mathrm{~cm}$ VAS.
TABLE 2

Physiological measures during virtual game sessions

\begin{tabular}{lcc}
\hline & \multicolumn{2}{c}{ Virtual game session } \\
\cline { 2 - 3 } Measure & Pre & Post \\
\hline Heart rate, beats/min & $88.1 \pm 14.8$ & $101.9 \pm 18.0^{*}$ \\
Dyspnea (Borg scale) & $1.5 \pm 1.1$ & $3.2 \pm 1.2^{*}$ \\
$\mathrm{SpO}_{2}, \%$ & $93.7 \pm 2.8$ & $90.7 \pm 4.6^{*}$ \\
\hline
\end{tabular}

Data presented as mean $\pm S D$. ${ }^{\star} P<0.001 . \mathrm{SpO}_{2}$ Oxygen saturation

Patients also reported a mean score of $8.0 \pm 2.6 / 10$ as to whether they would recommend the program to another patient with COPD and 7.0 $\pm 3.7 / 10$ when asked if they would consider purchasing a VGS. According to the modified Canadian Internet Use Survey questionnaire administered at baseline, approximately $97 \%$ of patients reported having familiarity with at least one type of technology, such as cell phone, computer, Internet and game consoles. Thirty nine per cent of these patients reported having access to computer games or a game console.

\section{DISCUSSION}

The present pilot study demonstrated that patients with moderate to very severe COPD were able to participate in an adjunct program using the Wii VGS. This program was safe, feasible and enjoyed as an additional form of exercise. Changes in physiological parameters, such as mean $\mathrm{HR}$, dyspnea and mean $\mathrm{SpO}_{2}$, indicate moderately challenging physical activity. This was associated with minor transient side effects. Adherence and attendance rates of $76 \%$ and $64 \%$, respectively, show adequate compliance with the adjunct program.

The merits of exercise for patients with COPD are now well known $(16,17)$. Aerobic and strength training increase exercise tolerance, decrease breathlessness and fatigue, improve quality of life and reduce the use of health care services $(18,19)$. Despite the benefits of exercise for patients with COPD, one of the greatest challenges remains adherence to an exercise program (19). Previous studies have described the decrease in adherence to physical exercise following PR (20). This may be particularly true for patients with severe COPD who are more sedentary and less likely to be able to attend a PR program or gym $(16,17)$. Consequently, creative solutions are needed to maintain motivation and activity by patients in their preferred environment. The use of virtual technologies to encourage activity is evolving, and has been tested in various research and clinical settings $(6,21,22)$; however, its use in COPD is novel. In fact, VGS may prove to offer a timely, low-cost solution with its relative ease of use $(23,24)$ compared with some traditional exercise modalities. This is particularly important in view of the lack of availability and attendance to PR programs, and the low adherence to exercise.

Patients with severe COPD, such as those in our pilot study, are at great risk for nonadherence to exercise. By including patients admitted for inpatient PR, we were able to closely monitor intensity and the physiological responses to VGS exercise, as well as to conduct multiple safety evaluations. We examined ways of using commercially available games for purposes of PR. Games were evaluated for their utility in training the upper and lower body with the objective of reproducing very similar body movements as those completed during regular PR sessions. Our results indicate that patients increased their HR and rated their dyspnea level at moderate intensity, as is expected with exercise. Interestingly, although it might be expected that patients playing in the seated position would have reduced energy expenditure, overall physiological results indicated otherwise. Thus, even individuals using a modified approach were able to exercise adequately. Our results were consistent with those found in a pilot study of five patients with COPD using a computer-based entertainment program (Wii) who were shown to have exercised at $52 \%$ to $82 \%$ of their peak oxygen consumption measured during an incremental shuttle walk test $(7,8)$. In view of these results, we believed that patients able to participate in our pilot study would achieve an adequate level of exercise similar to that attained in regular PR. 
Most importantly, we were striving for a proof of concept. Patients with very severe lung disease were able to actively engage in a VGS that proved safe and enjoyable. Patient safety and well-being was a main consideration in the present study. Adverse events observed during the course of the trial were minor and transient and, as such, this program was believed to be safe in this patient group.

Compliance with PR is known to vary between $56 \%$ and $88 \%$, with completion rates of $21 \%$ to $69 \%(16,17,25-27)$. The overall attendance rate in our study was $64 \%$, which is consistent with that previously demonstrated. Furthermore, $76 \%$ of patients adhered to at least $50 \%$ of sessions offered, and $32 \%$ of patients asked for extra sessions. Possible reasons for reduced attendance to the adjunct virtual game program may be explained by an already demanding PR schedule, which, as the primary goal of admission, patients were expected to attend. Moreover, this being a study, patient participation in the VGS sessions was voluntary, likely playing a role in adherence to the adjunct program.

Results regarding enjoyment measured using a VAS indicated a highly positive reaction to the virtual game program. Patients were so enthusiastic about participating in the study that many undergoing regular PR who heard about the adjunct program wanted to be included even when completion of accrual was achieved. Patient enjoyment is pivotal for motivation to exercise. Recreational activities included in PR programs seek to encourage movement, enjoyment and socialization in a population that is often isolated due to chronic illness. The addition of a virtual game program may be a way to provide an enjoyable leisure activity. Consequently, although adherence rates found in the present study were lower than that in the regular PR program, these results are encouraging for future use of VGS as an additional modality to PR, or even for home-based use.

One of the concerns we had before initiation of the present study involving a predominantly older population was the potential lack of comfort with technology. As such, we decided to survey the patient population to identify their familiarity before the first session. The results showed that approximately $97 \%$ of patients reported having familiarity with at least one type of technology such as cell phone, computer or Internet access. Furthermore, 39\% reported having access to computer games or a game console. This information is encouraging and consistent with a trend toward increased utilization of technology by seniors (28). Therefore, the perceived barrier to using virtual game technology in the elderly may be overestimated.

There were several limitations to our study. First, it was a pilot project designed to explore issues of feasibility, safety and enjoyment. It was beyond the scope of the present study to measure efficacy, which would have ideally been explored in a randomized controlled trial. Albores et al (8) showed that COPD patients using a computer-based entertainment program exercised at levels ranging from $52 \%$ to $82 \%$ of their peak oxygen consumption, which was assessed during incremental shuttle walk test. This estimate of level of exercise was determined using a portable telemetric system permitting continuous monitoring of HR, oxygen consumption, minute ventilation and inspiratory capacity. This confirmed that adequate work can be achieved using a VGS (8). We assessed physical parameters, such as dyspnea, $\mathrm{SpO}_{2}$ and $\mathrm{HR}$, to ensure patient safety and also to observe physiological response. It should be noted that these monitoring parameters are typical of our PR program and that patients are taught to use dyspnea as a subjective way of monitoring their exercise level. Despite the fact that these measurements are basic compared with the study by Albores et al (8), they give an indication of the level of exercise achieved.

\section{CONCLUSION}

Exercise using a VGS may prove useful and enjoyable as an adjunct to PR. Future studies may seek to investigate the use of this modality in the home environment encouraging patients with severe COPD to maintain physical activity following discharge from a standard program. Further testing of VGS in COPD should be performed using a randomized controlled trial.

ACKNOWLEDGEMENTS: The authors thank Chantal Robitaille $\mathrm{PhD}$ for her comments on the manuscript and Mount Sinai Hospital Foundation for its support of the project.

\section{REFERENCES}

1. Garrido PC, Diez JM, Gutierrrez JR, et al. Negative impact of chronic obstructive pulmonary disease on the health-related quality of life of patients. Results of the EPIDEPOC study. Health Qual Life Outcomes 2006;4:1-9.

2. Lacasse Y, Brooks D, Goldstein RS. Trends in the epidemiology of COPD in Canada, 1980 to 1995 . COPD and Rehabilitation Committee of the Canadian Thoracic Society. Chest 1999;116:306-13.

3. Stahl E, Lindberg A, Jansson S-A, et al. Health-related quality of life is related to COPD disease severity. Health Qual Life Outcomes 2005;3:1-8

4. Joshi M, Joshi A, Bartter T. Symptom burden in chronic pulmonary disease and cancer Curr Opin Pulm Med 2012;18:97-103.

5. Voss R. Wii for Therapy. <www.ehow.com3facts_6857234_wiitherapy.html> (Accessed June 2012).

6. Santos Mendes FA, Pompeu JE, Lobo AM, et al. Motor learning, retention and transfer after virtual-reality-based trainng in Parkinson`s disease - effect of motor and cognitive demands of games: A longitudinal, controlled clinical study. Physiotherapy 2012;98:217-23.

7. Albores J, Marolda C, Haggerty M, Gerstenhaber B, ZuWallack R. The use of a home exercise program based on a computer system in patients with chronic obstructive pulmonary disease. J Cardiopul Rehabil Prev 2012:1-6.

8. Albores J, Normandin E, Marolda C, Zuwallack R, Lahiri B. Physiologic variables observed in COPD patients while exercising with an interactive activity-promoting video game. Am J Respir Crit Care Med 2011:A183. (Abst)

9. O'Donnell DE, Hernandez P, Kaplan A, et al. Canadian Thoracic Society recommendations for management of chronic obstructive pulmonary disease- 2008 update. Highlights for primary care. Can Respir J 2008;15(Suppl A):1A-8A.
10. Vertesi A, Lever JA, Molloy DW, et al. Standardized Mini-Mental State Examination. Can Fam Phys 2001;47:2018-23.

11. Steffen TM, Hacker TA, Mollinger L. Age- and gender-related test performance in community-dwelling elderly people: Six-minute walk test, Berg balance scale, timed up \& go test, and gait speeds. J Am Phys Ther Assoc 2002;82:128-37.

12. Bogle Thorbahn LD, Newton RA. Use of the Berg balance test to predict falls in elderly persons. J Am Phys Ther Assoc 1996;76:576-83.

13. Selzler A-M, Simmonds L, Rodgers WM, Wong, EYL, Stickland MK. Pulmonary rehabilitation in chronic obstructive pulmonary disease: Predictors of program completion and success. J Chron Obstr Pulmon Dis 2012;9:538-45.

14. Van Der Molen B. Dyspnoea: A study of measurement instruments for the assessment of dyspnoea and their application for patients with advanced cancer. J Adv Nurs 1995;22:948-56.

15. Veenhof B, McKeown L. Canadian Internet Use Survey <www.statcan.gc.ca 2010> (Accessed January 28, 2013).

16. Vagaggini B, Costa F, Antonelli S, et al. Clinical Predictors of the efficacy of a pulmonary rehabilitation programme in patients with COPD. Respir Med 2009;103:1224-30.

17. Evans RA, Singh SJ, Collier R, Williams JE, Morgan MDL. Pulmonary rehabilitation is successful for COPD irrespective of MRC dyspnea grade Respir Med 2009;103:1070-5.

18. Goldstein RS, Hill K, Brooks D, Dolmage TE. Pulmonary rehabilitation - a review of the recent literature. Chest 2012;142:738-49.

19. Bourbeau J. Making pulmonary rehabilitation a success in COPD. Swiss Med Week 2010;140:1-7.

20. Soicher JE, Mayo NE, Gauvin L, et al. Trajectories of endurance activity following pulmonary rehabilitation in COPD patients. Eur Respir J 2012;39:272-8. 
21. Fung V, Ho A, Shaffer J, Chung E, Gomez M. Use of Nintendo Wii $\mathrm{Fit}^{\mathrm{TM}}$ in the rehabilitation of outpatients following total knee replacement: A preliminary randomised controlled trial. Physiotherapy 2012;98:183-8.

22. York J. How can 'Wii' enhance the effects of pulmonary rehabilitation? 2009 <www.nursingtimes.net>,

(Accesssed January 21, 2012).

23. Halton J. Virtual rhabilitation with video games: A new frontier for occupational therapy. Occ Ther Now 2008;9:12-4.

24. Deutsch JE, Borbely M, Filler J, Huhn K, Guarrera-Bowlby P. Use of low-cost, commercially available gaming console (Wii) for rehabilitation of an adolescent with cerebral palsy. Phys Ther 2008;88:1195-207.
25. Garrod R, Marshall J, Barley E, Jones PW. Predictors of success and failure in pulmonary rehabilitation. Eur Respir J 2006;27;788-94.

26. Scott AS, Baltzan MA, Fox J, Wolkove N. Success in pulmonary rehabilitation in patients with chronic obstructive pulmonary disease. Can Respir J 2010;17:219-23.

27. Sabit R, Griffiths TL, Watkins AJ, et al. Predictors of poor attendance at an outpatient pulmonary rehabilitation programme Respir Med, 2008;102:819-24.

28. Veenhof B, Timusk P. Online activities of Canadian boomers and seniors. 2009 <www.statcan.gc.ca> (Accessed January 28, 2013). 


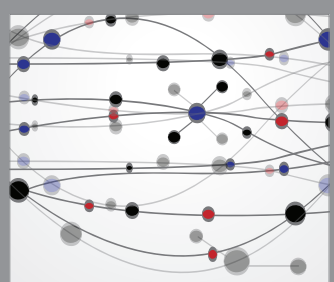

The Scientific World Journal
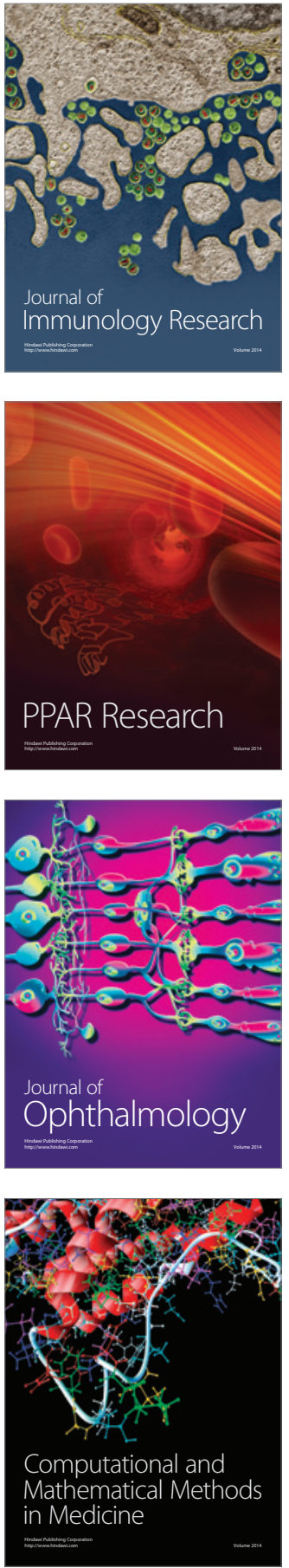

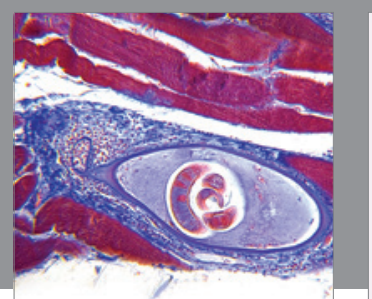

Gastroenterology Research and Practice

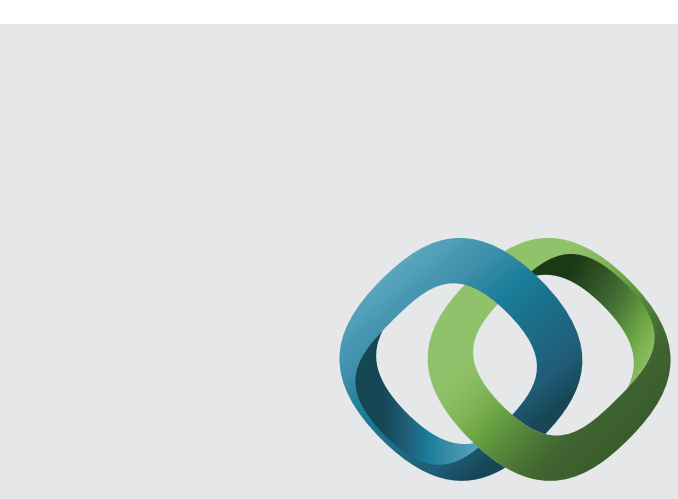

\section{Hindawi}

Submit your manuscripts at

http://www.hindawi.com
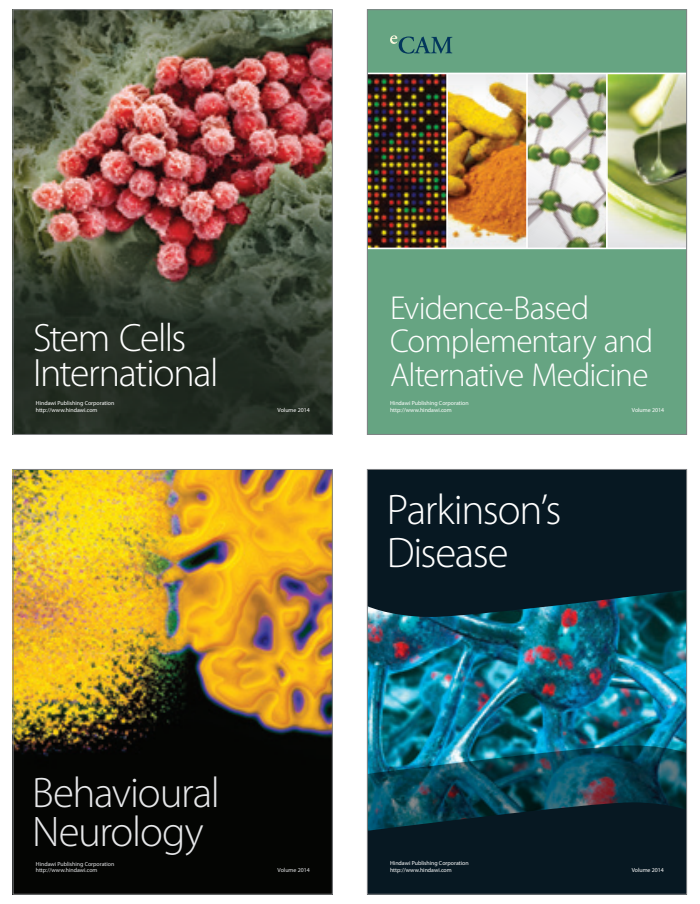
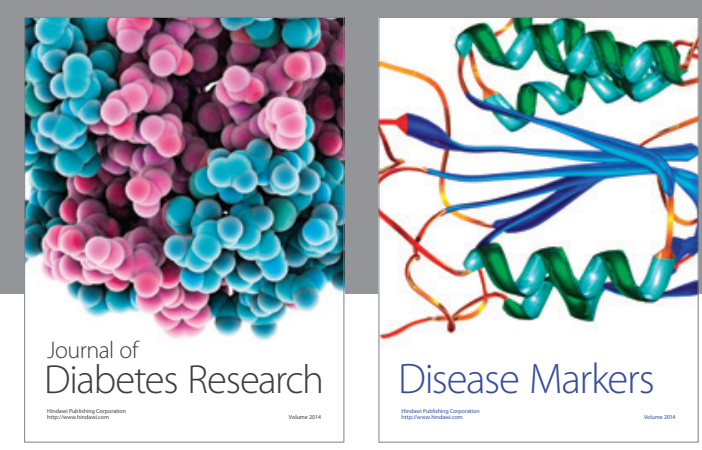

Disease Markers
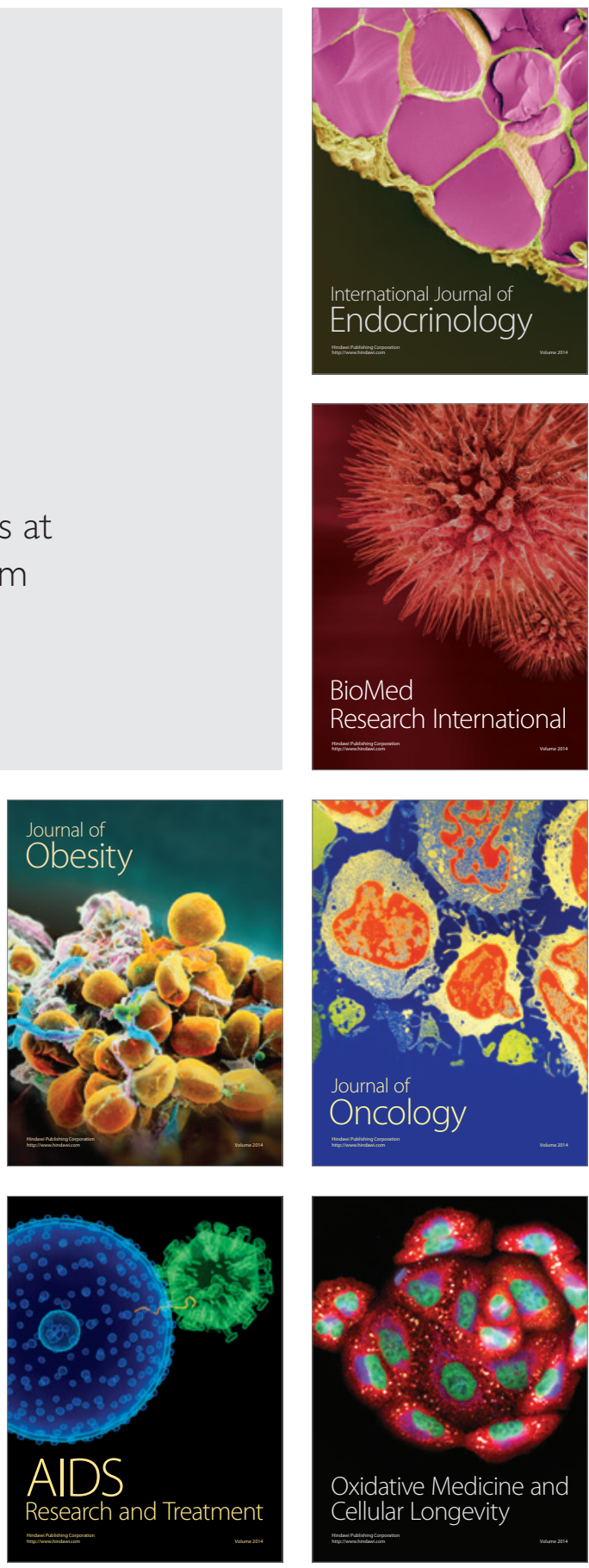